Seção Temática: Os Recursos Públicos em Disputa

Volume 11 - $2021 \mid$ n. 31

\title{
LicitaCon Cidadão como Ferramenta de Transparência na Análise de Parcerias Público-Privadas em Educação
}

\author{
Michele Vollrath Bento \\ Universidade Federal de Pelotas (UFPEL), Pelotas/RS - Brasil \\ Viviane da Silva Lemos \\ Universidade Federal de Pelotas (UFPEL), Pelotas/RS - Brasil \\ Maria de Fátima Cóssio \\ Universidade Federal de Pelotas (UFPEL), Pelotas/RS - Brasil
}

\section{Resumo}

O presente artigo é um recorte da pesquisa mais ampla que se propõe a constituir um banco de dados sobre as parcerias público-privadas nos municípios do estado do Rio Grande do Sul (RS), por meio de diferentes estratégias metodológicas de coleta das informações. Dentre as estratégias destaca-se neste artigo a utilização da ferramenta LicitaCon Cidadão (LC) como uma alternativa importante para identificar os formatos de contratos entre o poder público e setores privados, os recursos envolvidos, as instituições contratadas e as suas áreas de atuação. Analisam-se as transformações no papel do Estado, no contexto da globalização neoliberal, e a proposta em curso de modernização da máquina pública como elementos indispensáveis para a análise do cenário que propiciou a segurança jurídica e o movimento político em favor de uma forma particular de privatização da educação. Entende-se que o aprofundamento de estudos desta natureza permite a realização de novas pesquisas, colaborando na elucidação das implicações da inserção privada na educação pública e na formação de crianças e jovens, bem como na formulação de políticas públicas para o setor. Palavras-chave: LicitaCon Cidadão. Parceria Público-Privada. Transparência.

\section{LicitaCon Citizen as a Transparency Tool in the Analysis of Public-}

\section{Private Partnerships in Education}

\begin{abstract}
This article is an excerpt from a broader research that proposes to constitute a database on public-private partnerships in the cities of the state of Rio Grande do Sul (RS), through different methodological strategies for collecting information. Among the strategies, the use of the LicitaCon Cidadão (LC) tool is highlighted in this article as an important alternative to identify the formats of contracts between the government and private sectors, the resources involved, the contracted institutions and their areas of action. The transformations in the role of the State, in the context of neoliberal globalization, and the ongoing proposal to modernize the public machine are analyzed as indispensable elements for the analysis of the scenario that provided legal security and the political movement in favor of a particular form of privatization of education. It is understood that the deepening of studies of this nature allows for further research, helping to elucidate the implications of private insertion in public education and in the training of children and young people, as well as in the formulation of public policies for the sector.
\end{abstract}

Keywords: LicitaCon Citizen. Public-Private Partnership. Transparency. 
LicitaCon Cidadão como Ferramenta de Transparência na Análise de Parcerias Público-Privadas em Educação

\section{Introdução}

Este artigo é parte de uma pesquisa em desenvolvimento que tem como objetivo constituir um banco de dados das parcerias público-privadas em educação nos municípios do estado do Rio Grande do Sul (RS) ${ }^{1}$. A coleta de dados vem ocorrendo através de diversas estratégias metodológicas, tais como o instrumento de coleta de dados enviado aos municípios do estado por e-mail; a busca de notícias sobre parcerias nos sites oficiais das Prefeituras e Secretarias Municipais de Educação e informações sobre contratos contidos no site do LicitaCon Cidadão (LC), estratégias que se filiam à metodologia de etnografia de redes (BALL, 2014). A referida metodologia consiste em verificar o mapeamento da forma e do conteúdo das relações políticas em um campo particular. Portanto, a etnografia de rede objetiva utilizar novas formas de comunicação virtual e eletrônica, possibilitando amplo e detalhado acesso a dados dispostos digitalmente. Neste recorte da pesquisa far-se-á a análise do uso do LicitaCon Cidadão (LC), no intuito de aprofundar o conhecimento sobre as relações pactuadas entre os governos, principalmente no âmbito dos municípios, e Organizações da Sociedade Civil (OSCs), celebradas através de parcerias público-privadas (PPPs).

As PPPs foram introduzidas no Brasil pela Lei Federal $n^{0} 11.079 / 2004$, que estabeleceu normas gerais para licitação e contratação de parcerias público-privadas no âmbito da Administração Pública. Atualmente, a Lei no. 13.019/2014, conhecida como o marco regulatório das organizações da sociedade civil (MROSC), regulamenta o regime jurídico referente às parcerias entre a Administração Pública e as Organizações da Sociedade civil (OSC), sendo estas também consideradas PPPs. Assim, a atual regulamentação buscou exigir do poder público maior transparência na prestação de contas e comprovação de resultados das ações financiadas com recursos públicos. Sabe-se que as transações que envolvam financiamento estatal terão que ter suas informações publicizadas, com dados cada vez mais minudenciados, já que também através do MROSC os antigos convênios deram lugar aos instrumentos denominados termo de fomento, termo de colaboração e acordo de cooperação, de acordo com as características específicas de financiamento de cada parceria.

Dessa forma, este estudo busca conhecer como as informações sobre as parcerias em educação são evidenciadas através da plataforma LicitaCon Cidadão (LC), um sistema informatizado desenvolvido pelo Tribunal de Contas do Estado do Rio Grande do Sul (TCERS) para controle e monitoramento das licitações e contratos administrativos firmados pelos órgãos, poderes e entidades das esferas públicas municipal e estadual do RS, cujo emprego é obrigatório desde 02/05/2016 para todos os jurisdicionados da esfera municipal e, desde 02/01/2018, para a esfera estadual (TCE-RS, 2021).

Busca-se discutir sobre os pontos basais que envolvem as parcerias público-privadas em educação, que se ampliaram e se diversificaram em formatos e áreas de atuação nas últimas décadas, estando presentes nas redes públicas estaduais e municipais do País com cada vez mais intensidade. O principal argumento dos defensores dessas parcerias é de que os governos não conseguem fazer tudo sozinhos, quer seja do ponto de vista de oferta vagas,

1 O conteúdo do artigo faz parte da pesquisa: Mapeamento das parcerias público-privadas em educação nos municípios do estado do RS, em desenvolvimento pelo Núcleo de Estudos e Pesquisa em Políticas Educacionais/NEPPE/UFPEL e Grupo de Pesquisa em Relações Público-Privadas em Educação/GPRPPE/UFRGS. 
LicitaCon Cidadão como Ferramenta de Transparência na Análise de Parcerias Público-Privadas em Educação

quer seja do ponto de vista da qualidade, esta entendida como melhoria de indicadores mensuráveis através de avaliações em larga escala, ou seja, na lógica de resultados.

Realiza-se também uma discussão sobre o financiamento das parcerias públicoprivadas em educação e sobre a transparência dessas relações, bem como uma explicitação sobre o uso da ferramenta LicitaCon Cidadão (LC), para que seja possível a identificação dos contratos, dados e demais termos referentes às parcerias.

\section{Parcerias Público- Privadas: algumas conceituações}

A parceria público-privada surge no ordenamento jurídico brasileiro a partir da Lei Federal $n^{\circ}$. 11.079/2004, que a define, em seu art. $2^{\circ}$, como "o contrato administrativo de concessão na modalidade patrocinada ou administrativa". No mesmo artigo, nos parágrafos $1^{\circ}$ e $2^{\circ}$, estão definidos os conceitos de concessões patrocinadas e administrativas:

$\S 1^{\circ}$ Concessão patrocinada é a concessão de serviços públicos ou de obras públicas de que trata a Lei $n^{\circ} 8.987$, de 13 de fevereiro de 1995, quando envolver, adicionalmente à tarifa cobrada dos usuários contraprestação pecuniária do parceiro público ao parceiro privado.

$\S 2^{\circ}$ Concessão administrativa é o contrato de prestação de serviços de que a Administração Pública seja a usuária direta ou indireta, ainda que envolva execução de obra ou fornecimento e instalação de bens (BRASIL, 2004).

A legislação também estabelece no $\S 3^{\circ}$ do mesmo artigo o que não constitui parceria público-privada, qual seja, a concessão comum, sendo esta a concessão de serviços públicos ou de obras públicas de que trata a Lei $n^{\circ} 8.987$, de 13 de fevereiro de 1995, quando não envolver contraprestação pecuniária do parceiro público ao parceiro privado.

Assim, as parcerias público-privadas estabelecem vínculo obrigacional entre a administração pública e a iniciativa privada, através de um instrumento jurídico denominado contrato, cujo objetivo será a implementação ou gestão, total ou parcial, de obras, serviços ou atividades de interesse público, em que o parceiro privado assume a responsabilidade pelo financiamento, investimento e exploração do serviço (JUSTEN FILHO, 2018).

Na acepção de Di Pietro (2019, p. 190), a parceria público-privada é:

[...] o contrato administrativo de concessão que tem por objetivo (a) a execução de serviço público, precedida ou não de obra pública, remunerada mediante tarifa paga pelo usuário e contraprestação pecuniária do parceiro público, ou (b) a prestação de serviço de que a Administração Pública seja a usuária direta ou indireta, com ou sem execução de obra e fornecimento e instalação de bens, mediante contratação do parceiro público.

A partir da Emenda Constitucional (EC) no 19 de 1998, da Constituição Federal de 1988, foi legalmente possibilitado às instituições privadas associarem-se aos governos através dos seguintes tipos de contrato de gestão: termos de parceria, acordo de colaboração e de fomento às parcerias público-privadas propriamente ditas. Os três primeiros instrumentos estabelecem juridicamente as relações entre a esfera pública e organizações privadas sem finalidade lucrativa específica, enquanto o último regulamenta a transferência da atividade governamental para organizações lucrativas.

Do ponto de vista jurídico foram criadas as condições favoráveis à inserção dos setores privados no setor público, como uma forma particular de privatização, uma vez que se encontram presentes os instrumentos que levarão à terceirização, estabelecidos na Emenda 
LicitaCon Cidadão como Ferramenta de Transparência na Análise de Parcerias Público-Privadas em Educação

Constitucional (EC) n. 19/1998 e na Lei de Responsabilidade Fiscal (Lei Complementar no. 101/2000) (ADRIÃO et al., 2012). A concepção dos legisladores é de que o setor privado reúne as competências necessárias à prestação qualificada dos serviços públicos e o Estado, com a alteração das competências da União trazidas pela EC 14/1996 e a Lei de Diretrizes e Bases da Educação Nacional (LDB) (Lei n. 9.394/96), atua como mero responsável pela adequada coordenação dos serviços prestados (ADRIÃO et al., 2012).

Com a possibilidade de interferência direta da iniciativa privada junto ao setor público, destaca-se o importante questionamento de Di Pietro (2019, p. 302):

[...] qual a razão pela qual a Constituição estabeleceu normas sobre licitação, concurso público, controle, contabilidade pública, orçamento e as impôs para todas as entidades da Administração Pública? Será que as impôs porque se entendeu que elas são essenciais para proteger a coisa pública ou foi apenas por amor ao formalismo? E se elas são essenciais, como se pode conceber que, para escapar às mesmas, se criem institutos paralelos que vão administrar a mesma coisa pública por normas de direito privado, inteiramente à margem das normas constitucionais?

A expressão parceria público-privada pode se referir ainda à capacidade de intervir que o setor privado terá junto à administração pública, tomando para si, total ou parcialmente, atribuições originárias do poder público (ADRIÃO et al., 2012).

As PPPs resultam no afastamento do Estado das atividades imediatas atinentes ao setor da educação, restando apenas, sob sua tutela, o financiamento dos provedores, por meio de vales ou subsídios, bem como regular, fiscalizar e avaliar a prestação de serviços educacionais (ROBERTSON; VERGER, 2012).

Dessa forma, o privado assume a questão da qualidade, na lógica empresarial, através da reestruturação das condições de trabalho dos professores (revisão de contratos, adoção da concorrência e de incentivos), a definição curricular, materiais didáticos, gestão de sistemas, entre outros (ROBERTSON; VERGER, 2012).

Torna-se importante salientar que, nesse cenário de permeabilidade do Estado à inserção de atores privados, a responsabilidade pela materialidade de direitos não fica explícita, secundarizando-se o papel do Estado como responsável principal pela efetividade do direito à educação, especialmente em países nos quais os direitos sociais se apresentam extremamente fragilizados (PERONI; OLIVEIRA, 2019).

Por essa razão, também a democracia na esfera educacional foi relativizada, na medida em que as decisões no espaço escolar passaram a ser pautadas por indicadores externos, alheios aos processos e instâncias decisórias institucionais, tanto que as discussões e princípios educacionais contidos nos Projetos Político-Pedagógicos (PPPs) escolares não são mais objeto de análise e orientações, sendo substituídos por planos de metas e estratégias.

Assim, mesmo que continuem como instituições de propriedade pública, ao terem seus processos decisórios internos enfraquecidos, gestores, professores e servidores de escolas podem tornar-se meros executores, num flagrante movimento de privatização da educação, porém com financiamento estatal (PERONI; OLIVEIRA, 2019). 
LicitaCon Cidadão como Ferramenta de Transparência na Análise de Parcerias Público-Privadas em Educação

\section{As parcerias público-privadas: a educação como um negócio}

As reformas ocorridas no Brasil, a partir da década de 1990, tiveram o propósito de reestruturar o papel do Estado, em sintonia com o modelo de globalização neoliberal que se expandia em vários países, para além dos seus precursores (Inglaterra e Estados Unidos).

O Estado, para se tornar modernizado, foi incitado a assumir padrões de gestão gerenciais, voltado para a lógica de mercado, deixando seu caráter provedor para assumir a função de regulador da economia e das políticas sociais. Ao reduzir as funções que eram vistas como sendo atividades exclusivas do Estado, a educação também se tornou uma das funções dessa "empresa", que poderia ser administrada através do modelo gerencial e que buscava acima de tudo eficiência e qualidade total na prestação de seus serviços ao "cliente".

O que se pode verificar, na prática, é a transformação da educação em uma relação de consumo, em que o aluno é o consumidor, representado por seus pais, e o fornecedor é aquele que presta o serviço de ensino. Assim, para a escolha da escola pelos pais e estudantes, organiza-se o setor de educação com a lógica de mercado, operando de forma livre e pautado por informações sobre: natureza e qualidade da educação oferecida pelos vários fornecedores, vigência de incentivos que levem aos objetivos esperados; mecanismos de regulação seguros a fim de garantir os interesses dos investidores privados e proteção da concorrência desleal entre os fornecedores, bem como sistema de avaliação que forneça dados para o sistema de informação, retroalimentando a rede (ROBERTSON; VERGER, 2012).

Rossi, Lumertz e Pires (2017) destacam que, a partir desse período, há uma proliferação de Organizações Não Governamentais (ONG), Organizações Sociais (OS) e parcerias público-privadas (PPPs) prestando assessorias e consultorias para as secretarias de educação de estados e municípios e escolas, apesar da complexidade das características políticas e sociais do fenômeno da educação. Vale ressaltar que o impacto da atuação dessas entidades no Brasil se tornou extremamente significativa, pois somente o Instituto Ayrton Senna, por exemplo, é responsável por vários programas e ações educacionais que incidem sobre a formação de cerca 3 milhões de estudantes brasileiros, somente no ano de 2020 , conforme seu Relatório anual referente a 2020 publicado no site da entidade.

Outro exemplo que se pode citar é a empresa EY, líder global em auditoria, impostos, transações e consultoria, que fomenta e evidencia as parcerias público- privadas celebradas nos estados brasileiros, apresentando os projetos de desestatização do estado da Bahia e do estado de São Paulo como cases em seu site. Ainda a EY-Parthenon, em seu estudo publicado em novembro de 2020 , esclarece e incentiva a participação do setor privado na educação pública, como forma de propiciar o acesso à educação de qualidade com redução de gastos.

Em seu relatório, a empresa afirma que, apesar de ainda não ser consenso, as PPPs já obtiveram ótimos resultados em diversos países, deixando o setor privado atuar em frentes extremamente importantes como planejamento, governança e monitoramento de políticas educacionais. A presença de novos atores e novas fontes de recursos na educação tende a ser vista como a solução de todos os problemas, enfraquecendo o papel do Estado e descredenciando a capacidade dos servidores públicos em gerir a educação e suas fontes vinculadas. 
LicitaCon Cidadão como Ferramenta de Transparência na Análise de Parcerias Público-Privadas em Educação

No estudo da EY (2020), os modelos de PPPs a serem analisados para implementação no Brasil são Vouchers, Escolas subsidiadas, Escolas contratadas e Build-Operate-Transfer.

Dentre os desafios na gestão da política educacional em tempos de gerencialismo está o fato de o mercado buscar cada vez mais desvalorizar o que é público, elencando críticas como eficiência duvidosa, educação precária na primeira infância, baixa capacitação dos professores, gestão administrativa ineficiente, infraestrutura inadequada, altos gastos e pouco investimento como causas dos principais problemas identificados do sistema educacional público brasileiro, tendo as PPPs como alternativa, sendo ferramenta essencial para favorecer a eficiência do sistema educacional e as restrições fiscais do governo, de acordo com seus formuladores.

Propostas milagrosas e com o intuito de confundir a sociedade e também a comunidade escolar esbarram na forma como essas promessas serão financiadas. De modo geral, a intervenção do mercado e seu discurso de eficiência, eficácia e qualidade acabam por onerar o governo por um longo prazo, tornando-o responsável, além das despesas, pelo risco de todo o processo, caso este não "dê certo" ou não consiga atingir os resultados esperados, sendo algo que deve ser pensado com muito cuidado já que a referida temática se mostra extremamente sensível e relevante.

Cada vez mais empresas do ramo financeiro e de prestação de serviços estão interessadas em investir no ramo da educação. As chamadas edu-business são para os investidores mais uma oportunidade de rendimento, já que os produtos educacionais podem ser vistos como amplamente replicáveis e rentáveis, uma vez que o desafio da qualidade na educação é recorrente, principalmente em países em desenvolvimento. Cabe destacar o conceito de edu-business, que poderia ser identificado como os negócios globais em educação, posto em prática pela intensa atuação das empresas educacionais multinacionais (BALL, 2014).

De maneira imediatista, nenhuma solução parece melhor do que a de implementar uma política que teve bons resultados em diversos países deste e de outros continentes sem ser necessário avaliar as diferenças e especificidades de cada realidade.

O desafio para os pesquisadores em parcerias público-privadas em educação está em conseguir identificar de maneira clara as informações relacionadas a essas parcerias. Se envolvem recursos públicos ou privados, quais as contrapartidas que o governo vai dar, se vai ceder instalações, mão de obra, materiais, qual o período e até mesmo o objeto da parceria? Dessa forma, é extremamente relevante a utilização da LC como forma de evidenciar, de maneira democrática, os dados das parcerias para a sociedade em geral.

\section{Governança e transparência das parcerias na educação}

Entende-se que a implementação das parcerias foi amplamente respaldada, pelas orientações governamentais para a gestão pública no Brasil, desde o Plano Diretor para a Reforma da Administração e Aparelho do Estado (PDRAE), em 1995, sendo permitida pela legislação vigente a ampliação do controle sobre a atuação das administrações públicas, em especial as de nível local. Ademais, estimulou-se a delegação, por parte de tais instituições, das responsabilidades assumidas, especialmente se relativas às políticas sociais, para a iniciativa privada (ADRIÃO et al., 2012). 
Muito embora existam espécies diferentes de PPPs, há uma base comum a todas e um conjunto de ideias programáticas que levam à continuidade do liberalismo econômico (ROBERTSON; VERGER, 2012). Na seara ideológica, que fundamenta o instituto das PPPs, pode-se encontrar a articulação do neoliberalismo com o neoconservadorismo, tendo em vista que os neoliberais consideram o Estado ineficiente e os neoconservadores veem o Estado sempre sobrecarregado de demandas levantadas por aqueles que não merecem atenção (ROBERTSON; VERGER, 2012).

Com a abertura do setor educacional, seria criado um meio receptivo ao ingresso do setor privado na esfera educacional, incentivando o ingresso da classe empresarial nessa área, tornando o Estado não totalmente ausente desse processo, porém com suas funções originárias totalmente alteradas, sendo apenas financiador e regulador:

\begin{abstract}
No entanto, para esta rede de empreendedores de políticas, o papel do Estado na gestão da educação é importante para minimizar as falhas de mercado e para responder às preocupações de equidade. PPPs são, portanto, o guarda-chuva perfeito, pois enquanto o propósito subjacente e as lógicas de gestão da educação são garantidos de acordo com a lógica de mercado, dada a presença do setor privado como responsável pela oferta, o Estado assegura o ambiente político favorável e, o mais importante, o seu financiamento (ROBERTSON; VERGER, 2012).
\end{abstract}

Enquanto ferramenta de governança, sob a ótica da nova gestão pública, as PPPs se mostram como uma espécie de solução para a educação, uma vez que dizem solucionar questões complexas, relacionadas à temática do desenvolvimento, até os dias atuais (ROBERTSON; VERGER, 2012).

De forma conceitual, entende-se a governança como uma maneira às organizações e empresas, de natureza privada, quer sejam multilaterais, transnacionais e internacionais, atuantes no mercado global, de abarcar as atividades inerentes ao Estado. Na esfera educacional, alerta para o governar como sendo mais que uma atividade do Estado (ROBERTSON, 2013).

Nesse sentido, também aduz Cóssio (2018):

Governança não é sinônimo de governabilidade, nem tem como objeto de estudo a arquitetura institucional de um dado sistema jurídico-político. $O$ seu significado é mais aberto e distintivo, na medida em que se refere à análise dos padrões de articulação e cooperação entre os atores e os arranjos institucionais que coordenam os sistemas sociais.

Assim, aqueles que defendem as PPPs salientam que o Estado é o principal responsável pela ausência de qualidade, sendo cabível sua remoção da condução da educação, bem como sua substituição na gestão educacional por setores privados, compostos inclusive por atores internos ao sistema educacional, como professores, pais e alunos. Porém, também não se tem garantias sobre o que as parcerias público-privadas vão entregar à sociedade no que tange à educação, já que, num fenômeno que envolve tantas variáveis, a única certeza que se tem é que procedimentos como a transparência e a divulgação de dados de maneira clara e organizada são uma regra, validando-se assim o procedimento de coleta de dados que será evidenciado na próxima seção. 


\section{Descrição metodológica do procedimento de coleta de dados}

O procedimento de coleta de dados no site da LC foi considerado o mais adequado dentre as estratégias analisadas pelo grupo de pesquisa, tendo em vista que as informações a serem pesquisadas, quais sejam, as parcerias público-privadas na área da educação, são efetivadas através de instrumentos específicos, legalmente previstos.

Os referidos instrumentos podem ser: contratos, convênios, termos de fomento ou termos de cooperação, de acordo com as especificidades de cada situação, através de alguma das modalidades de licitação, previstas em lei específica. Cabe ressaltar que a licitação é o meio através do qual o poder público efetua suas contratações, assim definido como um procedimento administrativo destinado à seleção da melhor proposta dentre as apresentadas por aqueles que desejam contratar com a Administração Pública.

A seguir se apresentam os procedimentos para acesso à ferramenta:

Figura 1 - Representação gráfica do acesso às informações do LicitaCon Cidadão

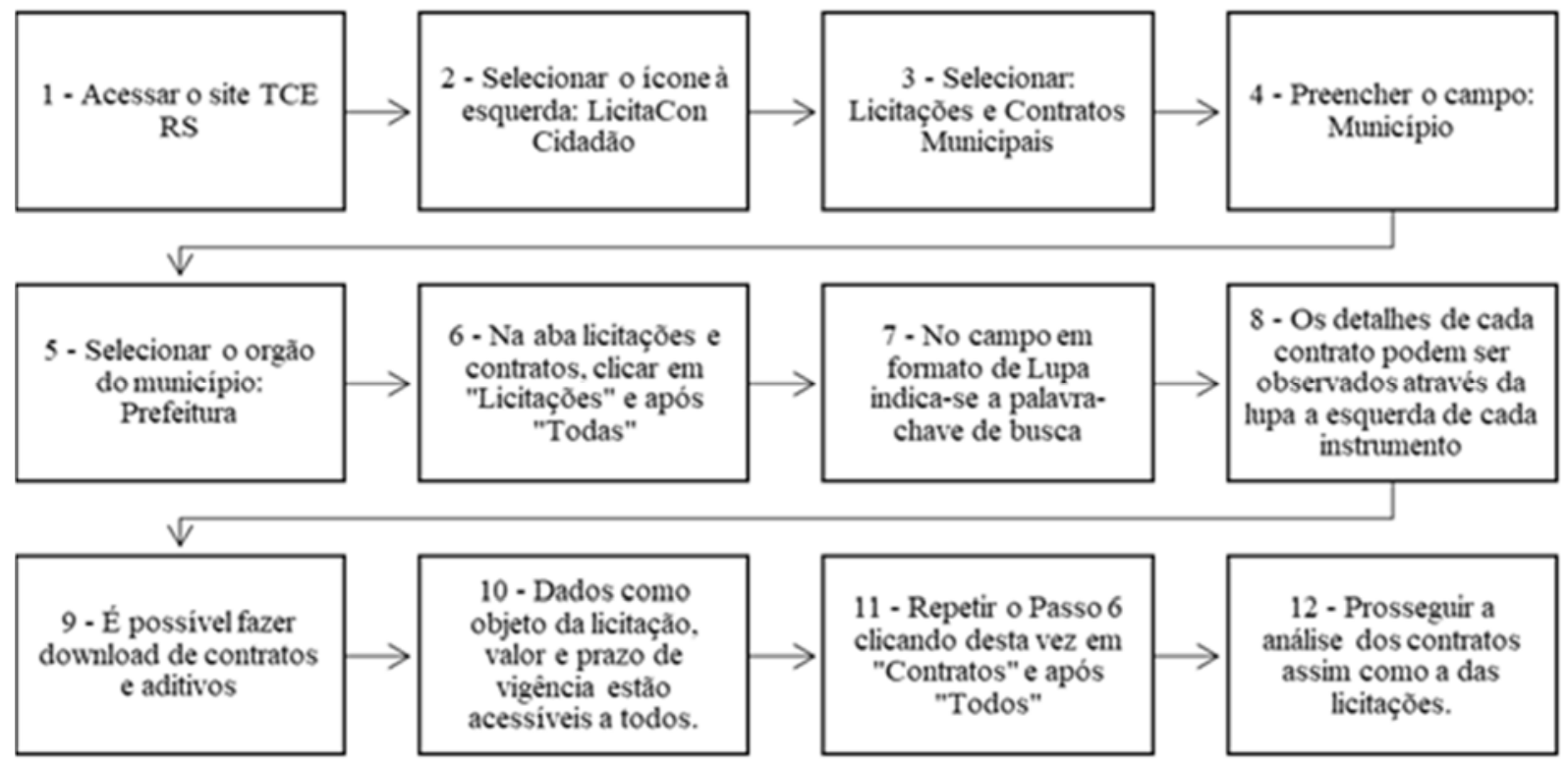

Fonte: Elaboração do autor com dados da pesquisa (2021).

Conforme elencado no elemento gráfico, este é, de maneira resumida, o percurso metodológico de coleta de dados desenvolvido através da plataforma LicitaCon Cidadão (LC). Destaca-se que, por meio de uma pesquisa de fácil acesso, pode-se viabilizar a identificação de inúmeros dados obtidos por intermédio de parcerias firmadas entre entidades da sociedade civil e os entes públicos de esfera estadual e municipal.

Na pesquisa que está sendo desenvolvida, contemplada pela parte descrita neste artigo, ocorre um filtro que analisa o último mandato do executivo municipal, de 2017 a 2020, sendo possível analisar as parcerias firmadas nesse período, através de notícias veiculadas nas páginas oficiais dos municípios. A segunda fase da coleta de dados verifica os contratos de parcerias público-privadas firmadas nesse mesmo ínterim e cadastradas na plataforma LicitaCon Cidadão, já que, nas notícias coletadas, de modo geral, os detalhes das parcerias não são informados. Dessa forma, dados como objeto do contrato, vigência, contrapartida, 
LicitaCon Cidadão como Ferramenta de Transparência na Análise de Parcerias Público-Privadas em Educação

valores financeiros e características da prestação de contas, necessárias para esses recebimentos, são relevantes para que seja possível identificar e validar os ganhos prometidos por essas vinculações com a administração pública.

O acesso aos contratos e às licitações traz à comunidade, através da ferramenta LC, a oportunidade de conhecimento sobre as relações entre público e privado, normalmente pouco difundidas. A compra de vagas da educação infantil, aquisição de material didático, formação de professores, são algumas das atividades analisadas dentro da pesquisa, tendo relação direta e indireta com diversas parcerias.

Vale ressaltar que, para uma pesquisa menos aprofundada, os dados presentes na tela inicial do sistema já trazem informação de extrema relevância, como Órgão, Objeto Contratado com CNPJ, data da assinatura, Vigência, Prazo, Valor Inicial e Valor Atual da parceria.

\section{Considerações Finais}

A pesquisa em desenvolvimento objetiva produzir um banco de dados sobre as parcerias público-privadas no período de 2017-2020 nos municípios do estado do RS, visando subsidiar o aprofundamento de pesquisas na área, após evidenciar a escassez de informações sobre o tema, além de contribuir com informações para a formulação de políticas públicas.

Este artigo é um recorte da pesquisa mais ampla e buscou situar o contexto econômico, social e político contemporâneo em que emergem de forma mais evidente as relações entre o público e o privado, destacando as transformações no papel do Estado, na esteira das mudanças do modelo capitalista. A Nova Gestão Pública (gerencialismo) e a governança são conceitos centrais para a compreensão da expansão da lógica mercantil na educação e, portanto, da criação de ambiente propício para a inserção do empresariado na educação pública, atuando na formulação de políticas e oferta de diversos serviços entendidos como essenciais para o alcance da qualidade.

As duas primeiras etapas da pesquisa, que consistiram em instrumento de coleta de dados enviado aos 497 municípios do estado do RS e pesquisa nos sites oficiais das prefeituras e secretarias municipais de educação, buscando informações referentes às parcerias, foram insuficientes para captar com mais clareza o formato e a existência dessas relações. Assim, recorreu-se ao uso da ferramenta LicitaCon Cidadão, criado pelo tribunal de contas do estado.

Através dessa metodologia observa-se que é possível aprofundar o conhecimento sobre a ocorrência das parcerias, seu objeto, obrigações da administração pública municipal, da organização da sociedade civil, dos recursos financeiros, incluindo dotação orçamentária para o pagamento, informações sobre a transferência e aplicação dos recursos, sobre a execução das despesas em vigência do contrato. Dados como os que evidenciam a importância da transparência exigida pelo MROSC são identificados nas seções que esclarecem as fases de monitoramento, acompanhamento e fiscalização da parceria, bem como na seção de prestações de contas, em que constam inclusive as possíveis sanções e glosas. A legislação prevê alterações contratuais, além da responsabilização e das sanções propostas a cada ente, podendo caber também renúncia ou rescisão contratual. 
LicitaCon Cidadão como Ferramenta de Transparência na Análise de Parcerias Público-Privadas em Educação

Percebe-se, dessa forma, a relevância da ferramenta LC na pesquisa em parcerias público-privadas no RS, já que, além de possuir vasta gama de informações, faculta acesso fácil e democrático à sociedade civil. Sugere-se que essa ferramenta seja usada como complemento do roteiro metodológico de pesquisas na área, trazendo dados validados oficialmente sobre as parcerias, que estarão ao alcance de todos e permitirão comparações e análises com mais fidedignidade.

Assim, pretende-se contribuir com pesquisas que visem a aprofundar o conhecimento na área, tornando visíveis as formas, objetivos, propósitos que subjazem às relações entre instituições privadas e setores públicos, e que impactam nos princípios da educação pública, reorientando-a, na gestão democrática, na formação de crianças e jovens e no projeto de sociedade.

\section{Referências}

ADRIÃO, Theresa et al. As Parcerias entre Prefeituras Paulistas e o Setor Privado na Política Educacional: expressão de simbiose? Educação \& Sociedade, Campinas, v. 33, n. 119, p. 533-549, abr.-jun. 2012.

BALL, Stephen J. Educação Global S. A.: Novas redes de políticas e o imaginário neoliberal. Tradução de Janete Bridon. Ponta Grossa: UEPG, 2014.

CÓSSIO, Maria de Fátima. A Nova Gestão Pública: alguns impactos nas políticas educacionais e na formação de professores. Educação, Porto Alegre, v. 41, n. 1, p. 66-73, jan./abr. 2018.

DI PIETRO, Maria Sylvia Zanella. Direito Administrativo. 32. ed. São Paulo: Editora Forense, 2019. JUSTEN FILHO, Marçal. Curso de Direito Administrativo. 13. ed. São Paulo: Revista dos Tribunais, 2018.

PERONI, Vera Maria Vidal; OLIVEIRA, Cristina Maria Bezerra de. O Marco Regulatório e as Parcerias Público-Privadas no Contexto Educacional. Revista Práxis Educacional, Vitória da Conquista, v. 15, n. 31, p. 38-57, jan./mar. 2019.

ROBERTSON, Susan. As Implicações Em Justiça Social Da Privatização Nos Modelos De Governança Da Educação: um relato relacional. Educação \& Sociedade, Campinas, v. 34, n. 34, jul./set. 2013.

ROBERTSON, Susan; VERGER, Antoni. A Origem das Parcerias Público-Privada na Governança Global da Educação. Educação \& Sociedade, Campinas, v. 33, n. 121, p. 11331156, out./dez. 2012.

ROSSI, Alexandre José; LUMERTZ, Juliana; PIRES, Daniela de Oliveira. As Parcerias Público-Privadas na Educação: cerceando autonomia e gestão democrática. Revista Retratos da Escola, Brasília, v. 11, n. 21, p. 557-570, jul./dez. 2017. 
LicitaCon Cidadão como Ferramenta de Transparência na Análise de Parcerias Público-Privadas em Educação

Michele Vollrath Bento possui graduação em Direito pela Universidade Federal de Pelotas UFPel (2003), Pós-Graduação Lato Sensu em Direito Processual pela Universidade Católica de Pelotas (UCPel) (2006), Programa Especial de Formação Pedagógica de Docentes para o Ensino Técnico de Nível Médio pelo Instituto Federal de Educação, Ciência e Tecnologia SulRio-Grandense (IFSul) - Campus Pelotas (2013), Mestrado em Direito pela Pontifícia Universidade Católica do Rio Grande do Sul (PUC/RS) (2015) e Doutoranda no Programa de Pós-Graduação em Educação (PPGE) da UFPEL desde 2018. Professora do IFSul - Campus Pelotas-Visconde da Graça (CAVG).

ORCID: http://orcid.org/0000-0003-3817-5538

E-mail:mivolb@gmail.com

Viviane da Silva Lemos é doutoranda em Educação pela Universidade Federal de Pelotas (UFPEL), Mestre em Contabilidade pela Universidade Federal do Rio Grande (FURG), Especialista em Controladoria e Finanças pela Universidade Católica de Pelotas (UCPEL) e Graduada em Ciências Contábeis pela Universidade Federal do Rio Grande (FURG). É Contadora lotada na Secretaria Municipal da Fazenda da cidade de Pelotas, RS. Atua, principalmente, nas linhas de pesquisa de Ensino e Pesquisa em Contabilidade, Análise de Políticas Públicas e Governança e Contabilidade Aplicada ao Setor Público.

ORCID: http://orcid.org/0000-0001-6339-5167

E-mail: viviane.slemos@gmail.com

Maria de Fátima Cóssio é professora associada da Universidade Federal de Pelotas (UFPel). Vinculada ao Departamento de Ensino da Faculdade de Educação, atua em cursos de Graduação/Licenciaturas e no Programa de Pós-Graduação em Educação. Orienta Iniciação Científica, Mestrado e Doutorado. É Líder do Núcleo de Estudos e Pesquisas em Políticas Educacionais/NEPPE/CNPQ. É Pró-Reitora de Ensino da Universidade Federal de Pelotas UFPel. Possui Graduação em Pedagogia, Especialização em Alfabetização, Mestrado e Doutorado em Educação na linha de pesquisa em Gestão e Políticas de educação na Universidade Federal do Rio Grande do Sul (UFRGS), Pós-Doutorado na Linha de Pesquisa em Políticas Educacionais e Trabalho na Universidade Federal de Santa Catarina (UFSC).

ORCID: http://orcid.org/0000-0003-1730-6877

E-mail: cossiofatima13@gmail.com 